\title{
Quasielastic Light Scattering and Structure of Nanodroplets Mixed with Polycaprolactone
}

\author{
Soheil Sharifi \\ Department of Physics, Faculty of Sciences, Ferdowsi University of Mashhad, Mashhad 91775-1436, Iran \\ Correspondence should be addressed to Soheil Sharifi; ssharifi@ferdowsi.um.ac.ir
}

Received 24 September 2013; Revised 10 May 2014; Accepted 12 May 2014; Published 23 June 2014

Academic Editor: Edyta Proniewicz

Copyright (C) 2014 Soheil Sharifi. This is an open access article distributed under the Creative Commons Attribution License, which permits unrestricted use, distribution, and reproduction in any medium, provided the original work is properly cited.

\begin{abstract}
The interaction of polycaprolactone (PCL) with droplets of a microemulsion is studied with quasielastic light scattering and small angle X-ray scattering At constant droplet size we vary the PCL concentration and there is clear evidence for an increasing attractive interaction of the droplets from structural investigations with small-angle X-ray scattering (SAXS). The collective diffusion coefficient $\left(D_{c}\right)$ of the droplets is monitored with quasielastic light scattering (QELS). We mainly focus on the variation of the dynamic behavior as a function of the PCL concentration and length scale (M.W. $=5000$ and 10000 ) in microemulsion. With increasing PCL concentration and length scale the dynamics of the system slow down. A hard sphere model with depletion potential can fit well the SAXS experiment of microemulsion mixed with PCL. The results show with increase of PCL on microemulsion the size of droplets is constant at $83 \AA$ but the size ratio of polymer to droplets is changing.
\end{abstract}

\section{Introduction}

Quasielastic light scattering is a very useful method to characterize the structure of microemulsion, polymers, and nanoparticles in solution [1-9].

If the scattering particles of solutions are moving, fluctuations in the scattered intensity with time are directly reflecting the so-called Brownian particle motion of the scattering particles (caused by thermal density fluctuations of the solvent). This is the case because of a change in the interference pattern with changing interparticle position, and correspondingly a change in the detected scattered intensity were measured at a given scattering angle [10-16].

The microemulsions are a mixture of water oil and surfactant that they can form in different shapes as water droplets to oil solutions or oil droplets to the water solutions phase. The microemulsions are optically transparent and they are good for optical experiments.

The $\mathrm{C}_{12} \mathrm{E}_{5}$ microemulsion consists of nanometer-size oil (decane) nanodroplets in water matrix stabilized by the pentaethylene glycol monododecyl ether $\left(\mathrm{C}_{12} \mathrm{E}_{5}\right)$. The structure and phase behavior of such microemulsions are well investigated. The mixture of microemulsion with polymer is an interesting topic on soft matter physics [17-20]. The interesting subject in this field is depletion effect [20] and network transition in the polymer/microemulsion mixture [21]. The depletion interaction was observed at 1925 and it is shown by adding soluble polymers to a colloidal mixture which led to the aggregation of the colloids. The first description of this phenomenon was given by Asakura and Oosawa at 1954. The depletion was observed in several polymer/microemulsion mixtures [20].

The PCL is a biopolymer that it is water-soluble and the solubility of PCL in water depends on the molecular weight and concentration of PCL [22]. The QELS is used to study the effect of PCL on motion of nanodroplets of $\mathrm{C}_{12} \mathrm{E}_{5}$ microemulsion. We know that the $\mathrm{C}_{12} \mathrm{E}_{5}$ microemulsion shows spherical oil surfactant to the water nanodroplet phase between $24^{\circ} \mathrm{C}$ and $30^{\circ} \mathrm{C}$ [23-25]. The increase of PCL on aqueous phase of $\mathrm{C}_{12} \mathrm{E}_{5}$ microemulsion can change free volume of solutions and the interaction between the nanodroplets (oil surfactant).

In this work, we study the effect of concentration and length scale of polycaprolactone (PCL) on droplets of $\mathrm{C}_{12} \mathrm{E}_{5} /$ water/decane by QELS and small angel X-ray scattering (SAXS). 


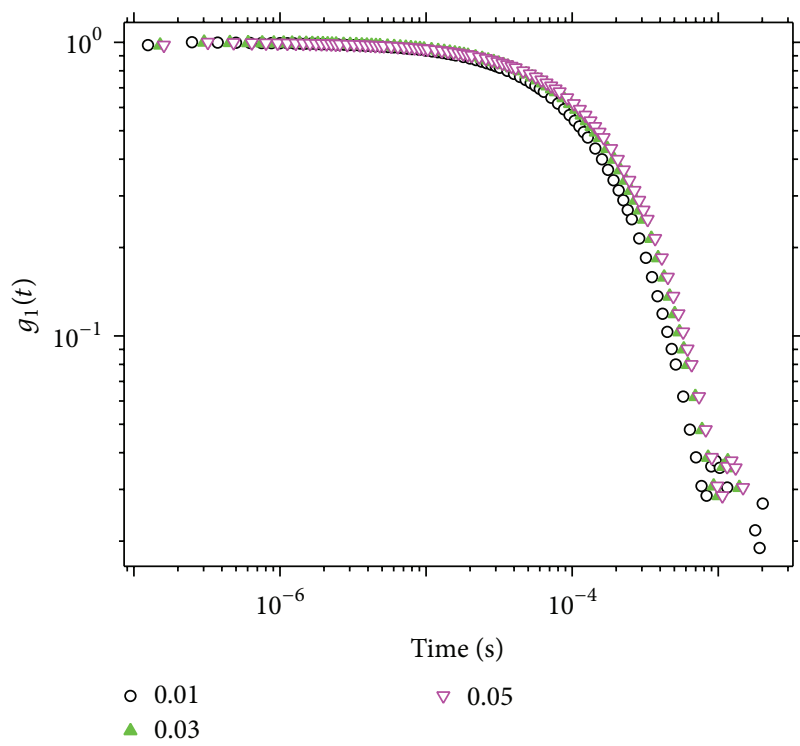

(a)

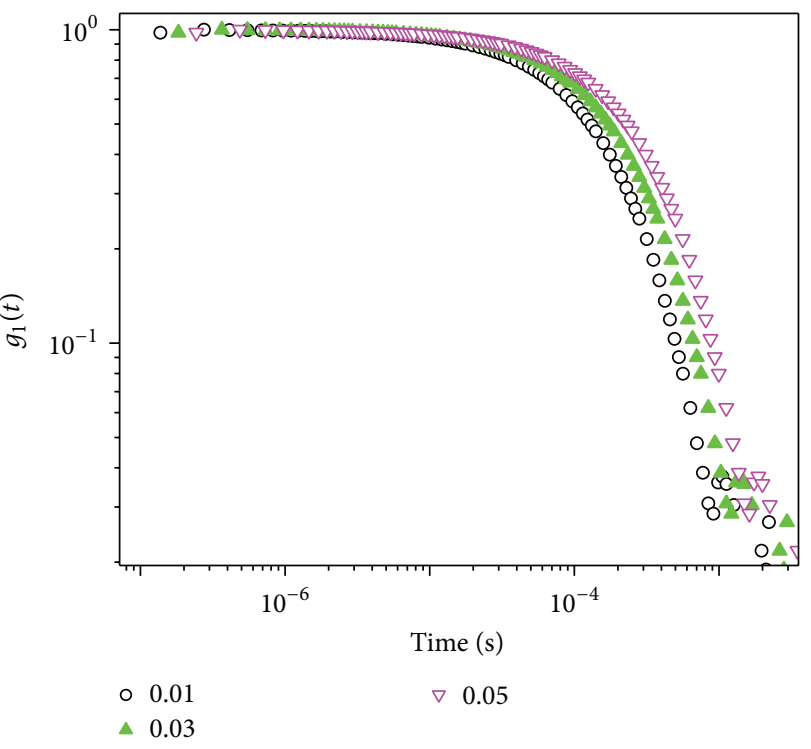

(b)

FIGURE 1: First-order field correlation function versus time for a mixture of $\mathrm{C}_{12} \mathrm{E}_{5}$ microemulsion with PCL at droplet mass fraction (0.2) and $m_{\mathrm{Dec}} / m_{\mathrm{C}_{12} \mathrm{E}_{5}}=1.08$ and different mass fractions of PCL (0.01, 0.03, and 0.05). (a) PCL with M.W. $=5000$ and (b) PCL with M.W. $=10000$.

\section{Experiment}

2.1. Materials and Methods. The pentaethylene glycol monododecyl ether $\left(\mathrm{C}_{12} \mathrm{E}_{5}\right)$ and $\mathrm{n}$-decane were obtained from Sigma-Aldrich. Polycaprolactone (PCL) with molecular weight (M.W. = 5000 and 10000) was optioned from Polysciences company, Eppelheim, Germany. The microemulsion was prepared by weight, in terms of surfactant-oil mass ratio of 1.08 and the mass fraction of droplets $\left(m_{f \text {,drop }}=\right.$ $\left.\left(m_{\text {Dec }}+m_{\mathrm{C}_{12} \mathrm{E}_{5}}\right) /\left(m_{\text {Total }}\right)\right)$, which varies by the respective mass of n-decane $\left(m_{\mathrm{Dec}}\right), \mathrm{C}_{12} \mathrm{E}_{5}\left(m_{\mathrm{C}_{12} \mathrm{E}_{5}}\right)$, and total sample mass $\left(m_{\text {Total }}\right)$. The samples of microemulsions with polymer were prepared by weight in terms of the mass fraction of triblock polymer $\left(m_{f \text {,poly }}=m_{\text {poly }} /\left(m_{\text {Total }}\right)\right)$ that $m_{\text {poly }}$ is the mass of polymer in the sample. The mixed samples were prepared at a constant surfactant-oil mass ratio of 1.08 with the different mass fractions of polycaprolactone (PCL) polymer. All samples were transparent at $25^{\circ} \mathrm{C}$.

2.2. Small Angle X-Ray Scattering. Small angle X-ray scattering (SAXS) measurements were performed using the pinhole SAXS instrument at Nanolab company (KNL, Iran). A X'Pert Pro MPD small angle X-ray from PANalytical was employed to obtain SAXS patterns. The experiments were done at a fixed wavelength of $\lambda=1.54 \AA$ and two different sample-detector distances.

2.3. Quasielastic Light Scattering. QELS measurements were performed using an ALV single-detector version compact goniometer system, from ALV-GmbH, Langen, Germany. The light source is a He-Ne laser, operating at a wavelength of $632 \mathrm{~nm}$, with vertically polarized light. It has been seen that particles in dispersion are in a constant, random Brownian motion and that this causes the intensity of scattered light to fluctuate as a function of time. The correlator used in a QELS instrument will construct the correlation function $g(t)$ of the scattered intensity $[1,2]$ :

$$
g(\tau)=\frac{\langle I(t) I(t+\tau)\rangle}{\left\langle I^{2}(t)\right\rangle},
$$

where $\tau$ is decay times. For a large number of particles in Brownian motion, the correlation function is an exponential decaying function of the correlator time delay $[1,2]$ :

$$
g(t)=A[1+B \exp (-2 \Gamma t)]
$$

where $A$ is the baseline of the correlation function and $B$ is an intercept of the correlation function. Consider the following:

$$
\Gamma=q^{2} D
$$

where $D$ is a translational diffusion coefficient and $q=$ $4 \pi n / \lambda \sin (\theta / 2)$, where $n, \lambda$, and $\theta$ are refractive index of dispersant, wavelength of the laser, and scattering angle.

\section{Results and Discussions}

Microemulsions were prepared by mixing $\mathrm{C}_{12} \mathrm{E}_{5}$ with ndecane and water at a constant droplet mass fraction (0.2) and $m_{\mathrm{Dec}} / m_{\mathrm{C}_{12} \mathrm{E}_{5}}=1.08$. Figures 1 and 2 show the correlation function $(g(\tau))$ as a function of decay time for $\mathrm{C}_{12} \mathrm{E}_{5}$ microemulsion mixed with PCL (M.W. $=5000$ and 10000). The correlation function of the scattered light intensity as a function of delay time showed a single exponential decay at all concentrations; see Figure 1.

From the inverse decay times, which vary linearly with the square of the momentum transfer, the collective diffusion 


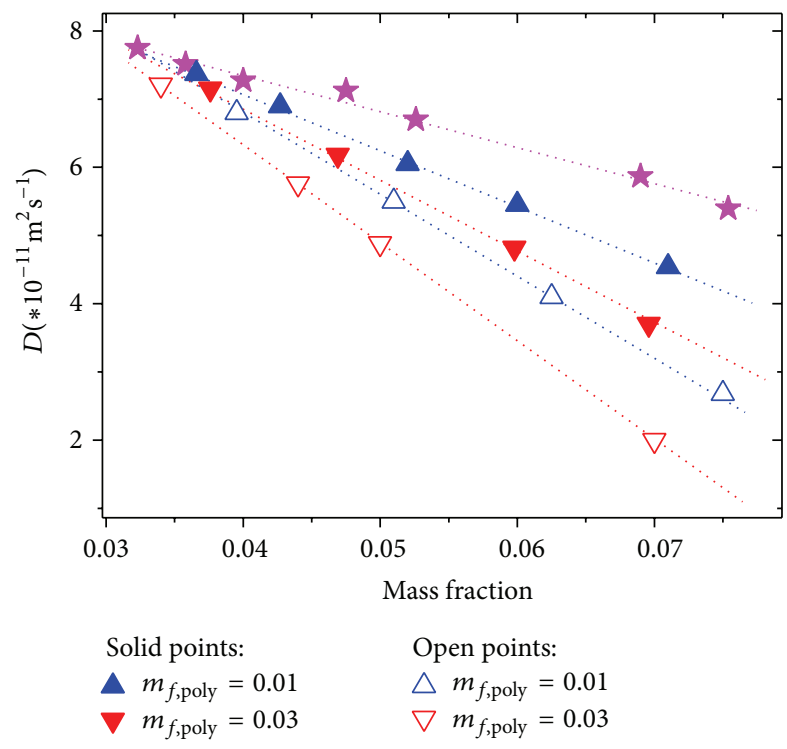

FIGURE 2: The collective diffusion of a mixture of $\mathrm{C}_{12} \mathrm{E}_{5}$ microemulsion with PCL at constant droplet mass fraction (0.2) and $m_{\text {Dec }} / m_{\mathrm{C}_{12} \mathrm{E}_{5}}=1.08$. The solid points are a mixture of $\mathrm{C}_{12} \mathrm{E}_{5}$ with PCL with M.W. $=5000$ and different polymer mass fractions and open points are a mixture of $\mathrm{C}_{12} \mathrm{E}_{5}$ microemulsion with PCL with M.W. = 10000 and polymer mass fraction.

coefficient $\left(D_{c}\right)$ was extracted as a function of the droplet mass fraction from (2) and (3).

The negative slope of collective diffusion coefficient as a function of droplet mass fraction of pure $\mathrm{C}_{12} \mathrm{E}_{5}$ microemulsion and polymer microemulsion shows attractive interaction between nanodroplets at microemulsion; see Figure 2 . The decreasing slope of collective diffusion coefficient as a function of mass fraction shows the increasing attractive interaction between the droplets; see Figure 2 .

In Figure 2, the mixture of microemulsion with two concentration polymer mass fractions $\left(m_{f, \text { poly }}=0.01\right.$ uptriangle solid points and $m_{f \text {,poly }}=0.03$ down-triangle solid points) of PCL (M.W. $=5000)$ and the open up- and down-triangle points are microemulsion with PCL (M.W. = 10000). It is clear with the collective diffusion coefficient of droplets decreasing with the increase of molecular weight and concentrations of PCL inside the microemulsion.

A study with QELS shows that the mixture of $\mathrm{C}_{12}-$ polyethylene oxide- (PEO-) $\mathrm{C}_{12}$ with $\mathrm{C}_{12} \mathrm{E}_{5}$ microemulsion induces a network between nanodroplets at $\mathrm{C}_{12} \mathrm{E}_{5}$ microemulsion that it is found that the increase of $\mathrm{C}_{12}-\mathrm{PEO}-$ $\mathrm{C}_{12}$ can produce fast and slow motions (collective diffusion coefficient) in the microemulsion [21], and the origin of those motions comes from connected and nonconnected nanodroplets inside the $\mathrm{C}_{12}-\mathrm{PEO}-\mathrm{C}_{12} / \mathrm{C}_{12} \mathrm{E}_{5}$ microemulsion These two motions were observed from correlation function $g(\tau)$ [21]. In our samples, the mixture of PCL with $\mathrm{C}_{12} \mathrm{E}_{5}$ microemulsion shows a motion (collective diffusion coefficient), so we can propose that PCL cannot be able to produce a network between the nanodroplets.

The depletion effect was observed in the mixture of polyethylene glycol (PEG) with $\mathrm{C}_{12} \mathrm{E}_{5}$ microemulsion
TABLE 1: The results of analyzing the SAXS experiments with hard sphere depletion model that is explained in the text; PDI is polydispersity of $\mathrm{PCL} / \mathrm{C}_{12} \mathrm{E}_{5}$ microemulsion.

\begin{tabular}{ccccccc}
\hline M.W. & $m_{f \text {,drop }}$ & $m_{f \text {, poly }}$ & Size ratio & Core & Core + shell & PDI \\
\hline \multirow{6}{*}{5000} & 0.2 & 0.008 & 0.43 & 72 & 83 & 0.2 \\
& 0.2 & 0.012 & 0.38 & 72 & 83 & 0.2 \\
& 0.2 & 0.025 & 0.31 & 72 & 83 & 0.2 \\
& 0.2 & 0.05 & 0.27 & 72 & 83 & 0.2 \\
& 0.2 & 0.08 & 0.24 & 72 & 83 & 0.2 \\
\hline \multirow{6}{*}{10000} & 0.2 & 0.007 & 0.51 & 72 & 83 & 0.2 \\
& 0.2 & 0.01 & 0.48 & 72 & 83 & 0.2 \\
& 0.2 & 0.02 & 0.46 & 72 & 83 & 0.2 \\
& 0.2 & 0.051 & 0.44 & 72 & 83 & 0.2 \\
& 0.2 & 0.08 & 0.41 & 72 & 83 & 0.2 \\
\hline
\end{tabular}

$[24,25]$, and these results show the increase in PEG concentration lead to increasing depletion effect. The studied depletion effect with QELS shows that the depletion effect can show one single motion (collective diffusion coefficient) and with increase of PEG concentration the collective diffusion is decreasing $[24,25]$.

In order to characterize the structure of the pure as well as the PCL containing $\mathrm{C}_{12} \mathrm{E}_{5}$ microemulsions we applied small angle $\mathrm{X}$-ray scattering. The scattered intensity as a function of $q$ for $\mathrm{C}_{12} \mathrm{E}_{5} /$ water/n-decane mixed with PCL is showed in Figure 3.

The scattered intensity is recorded with a 2-dimensional detector at a distance of $150 \mathrm{~cm}$ from the sample leading to an accessible range of scattering vectors $q=0.002 A^{-1}-0.15 A^{-1}$.

In order to extract the structural information from the $\mathrm{X}$ ray data, the following model will be employed. For analyzing the SAXS data's a hard sphere model with an attractive interaction is used. The results of analyzing are presented in Table 1.

The results of analyzing show the droplets size of microemulsion is constant at $R_{\mathrm{SAXS}}=8.3 \mathrm{~nm}$ for different concentrations and molecular weights of PCL.

The size ratio (size ratio of nanodroplet over polymer) is changing from 0.43 to 0.24 with increase of polymer concentration with low molecular weight $($ M.W. $=5000)$ and it changes from 0.51 to 0.41 for high molecular weight of polymer $(M . W .=10000)$. For both cases with the increase of concentration the length scale is decreasing.

One possibility to obtain information about internal structure of the particles is the indirect Fourier transformation (IFT) technique, resulting in the pair density distribution function, PDDF. This calculation is performed completely model-free and requires only a rough estimate of the maximum dimension of the particle. This method is useful for dilute systems.

The influence of the interaction effects can be computed by simultaneous calculation of the form factor and the structure factor, leading to a PDDF limited to intraparticle contributions. This can be achieved by the generalized indirect Fourier transformation (GIFT) technique [26].

The GIFT with a model with a depletion potential is used to extract the structure factor (Figure 4$)$. The $S(q)$ as 


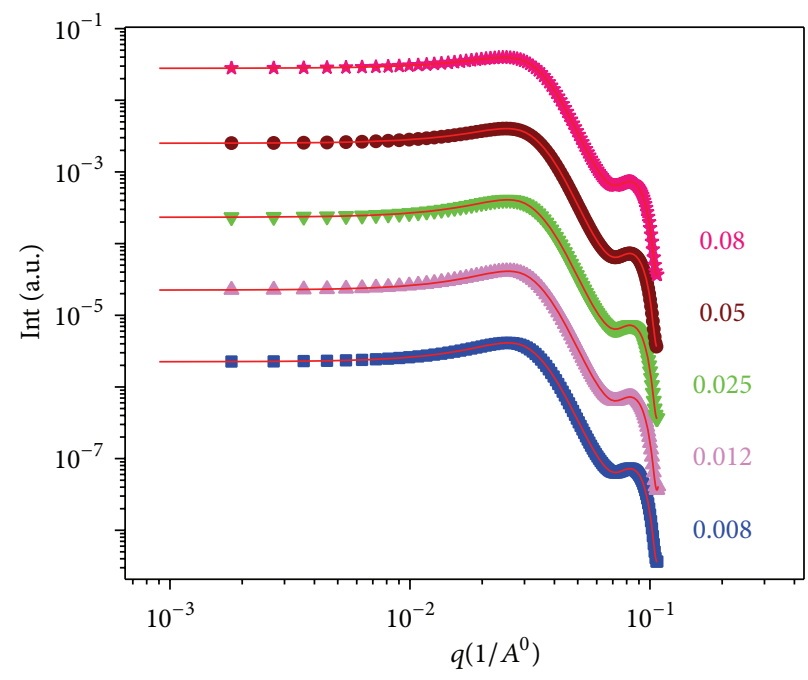

(a)

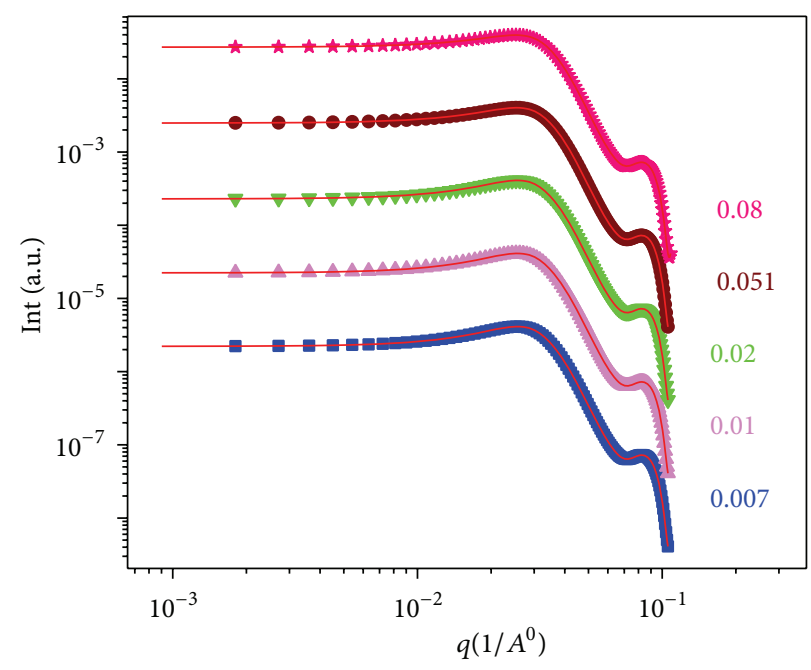

(b)

FIGURE 3: The SAXS experiment of a mixture of $\mathrm{C}_{12} \mathrm{E}_{5} /$ water/n-decane PCL at a constant droplet mass fraction $(0.2)$ and $m_{\mathrm{Dec}} / m_{\mathrm{C}_{12} \mathrm{E}_{5}}=1.08$ with different concentrations of PCL. (a) PCL with M.W. $=5000$ and (b) PCL with M.W. $=10000$.

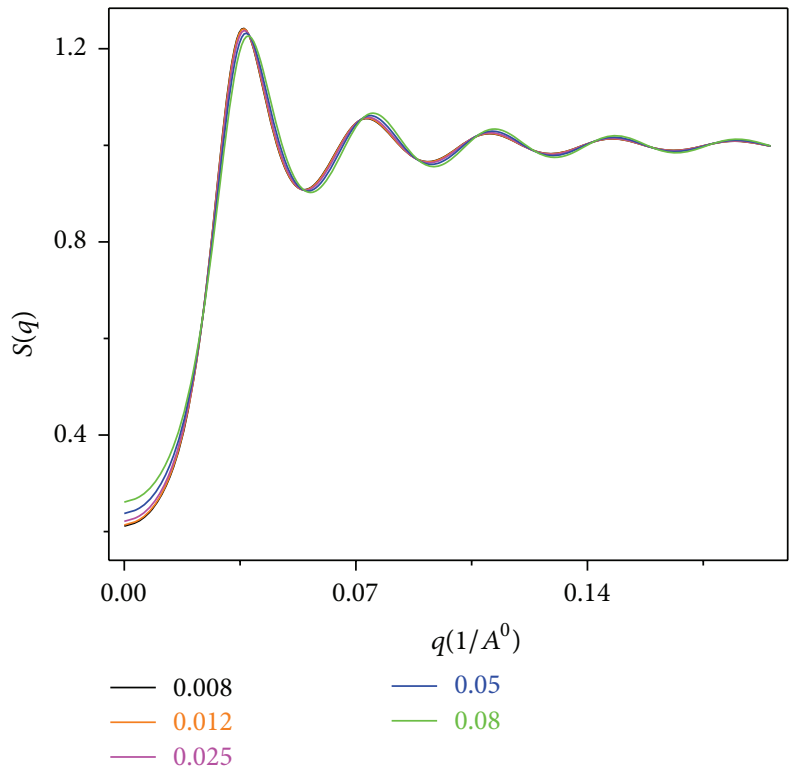

(a)

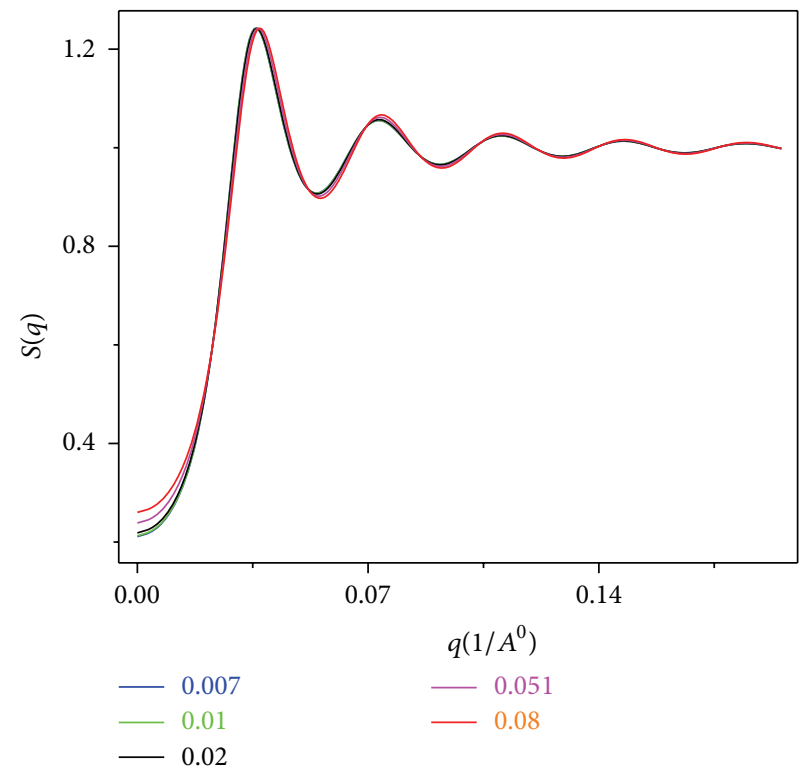

(b)

FIGURE 4: The structure factor of a mixture of $\mathrm{C}_{12} \mathrm{E}_{5} /$ water/n-decane PCL at a constant droplet mass fraction $(0.2)$ and $m_{\text {Dec }} / m_{\mathrm{C}_{12} \mathrm{E}_{5}}=1.08$ with different concentrations of PCL. (a) PCL with M.W. $=5000$ and (b) PCL with M.W. $=10000$.

a function of $q$ for a mixture of $\mathrm{C}_{12} \mathrm{E}_{5}$ microemulsion with different concentrations of PCL shows a peak at $q=0.036 \AA$ (Figure 4). This peak does not change with changing weight length and concentration of PCL but the value of the structure factor at low $q(q=0)$ increases with increasing of PCL concentration (Figure 5). The different molecular weights of PCL (5000 and 10000) have similar effect on intensity of low $q$ (Figure 5).

This behavior is similar to the mixture of PEG with $\mathrm{C}_{12} \mathrm{E}_{5}$ microemulsion $[24,25]$. In general, increasing of structure factor at low $q$ can explain type of interaction between droplets. The increasing of structure factor at low $q$ shows increase of attractive interaction between droplets. So, in our case we can propose that increase of PCL concentration can increase attractive interaction between nanodroplets. A study on the mixture of end-capped polymer with microemulsion shows that the narrow peck at structure factor describes the increase of order in systems [21]; in the case of our system the first peck is constant at PCL/ $\mathrm{C}_{12} \mathrm{E}_{5}$ microemulsion which explains the order of droplets does not change with increase of PCL concentration. 


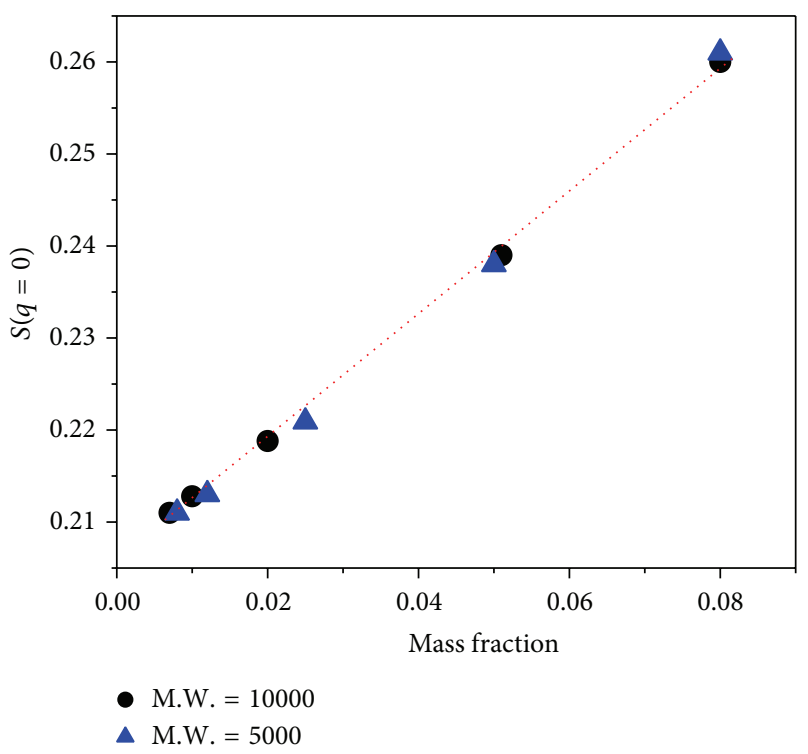

FIGURE 5: The structure factor of a mixture as a function of polymer mass fraction of $\mathrm{C}_{12} \mathrm{E}_{5} /$ water/n-decane at $q=0$ at a constant droplet mass fraction $(0.2)$ and $m_{\mathrm{Dec}} / m_{\mathrm{C}_{12} \mathrm{E}_{5}}=1.08$. The circle points are PCL with M.W. $=5000$ and up-triangle is PCL with M.W. $=10000$.

\section{Conclusions}

SAXS and QELS have been used to study the mixture of different weight lengths and concentrations of PCL mixed with $\mathrm{C}_{12} \mathrm{E}_{5} /$ water/n-decane microemulsion. The results show a depletion interaction due to the fact that the increase of amount of PCL can decrease the motion of nanodroplets inside microemulsion. The different molecular weights of PCL (5000 and 10000) have similar effect on attractive interaction. The SAXS data's could describe the depletion model quantitatively. The result of SAXS with data's shows the size of nanodroplets is constant but the size ratio is decreasing with increase of PCL in the microemulsion that it is due to aggregation of PCL in the solutions. The depletion effect can describe well the behavior of collective diffusion coefficient with increase of PCL concentrations.

\section{Conflict of Interests}

The author declares that there is no conflict of interests regarding the publication of this paper.

\section{References}

[1] B. J. Berne and R. Pecora, Dynamic Light Scattering: With Applications to Chemistry, Biology, and Physics, John Wiley \& Sons, 1976.

[2] C. S. Johnson and D. A. Gabriel, Lasers Light Scattering, John Wiley \& Sons, 1957.

[3] B. Chu, Laser Light Scattering: Basic Principles and Practice, American Press, 1974.

[4] J. Cieśla, A. Bieganowski, J. Narkiewicz-Michałek, and M. Szymula, "Use of a dynamic light scattering technique for
SDS/water/pentanol studies," Journal of Dispersion Science and Technology, vol. 34, no. 4, pp. 566-574, 2013.

[5] C. J. Doran, "Photon correlation spectroscopy and velocimetry," Optica Acta: International Journal of Optics, vol. 25, no. 3, pp. 271-272, 1978

[6] A. M. Bellocq, G. Fourche, P. Chabrat, L. Letamendia, J. Rouch, and C. Vaucamps, "Dynamic light scattering study of concentrated W/O microemulsions," Optica Acta: International Journal of Optics, vol. 27, no. 12, pp. 1629-1639, 1980.

[7] J. P. Boon and S. Yip, "Correlated dynamics and light scattering in microemulsions," Optica Acta: International Journal of Optics, vol. 29, no. 9, pp. 1167-1169, 1982.

[8] D. Caroline, "Measurement of suspended particles by quasielastic light scattering," Optica Acta: International Journal of Optics, vol. 31, no. 3, pp. 276-277, 1984.

[9] M. Weinberg, "Light scattering: iandau-placzek ratio and total intensity," Physics and Chemistry of Liquids, vol. 4, no. 2-3, pp. 163-170, 1974.

[10] P. R. Berman, "Light scattering," Contemporary Physics, vol. 49, no. 5, pp. 313-330, 2008.

[11] A. Cao, "Light scattering. Recent applications," Analytical Letters, vol. 36, no. 15, pp. 3185-3225, 2003.

[12] E. J. Derderian and T. B. MacRury, "Quasielastic light scattering on standard poly(styrene) latices," Journal of Dispersion Science and Technology, vol. 2, no. 2-3, pp. 345-358, 1981.

[13] N. B. Behzadi and S. Sharifi, "Light scattering and SAXS of spherical to cylindrical transition of $\mathrm{AOT} / \mathrm{H}_{2} \mathrm{O} /$ cyclohexane/PI," Physics and Chemistry of Liquids, vol. 52, no. 3, pp. 428435, 2014.

[14] N. Karimi, S. Sharifi, and M. Aliahma, "Photon correlation spectroscopy and SAXS study of mixture of $\mathrm{NaCl}$ with AOT Microemulsion at $\mathrm{X}=6.7$," Optics and Photonics Journal, vol. 2, no. 1, pp. 54-58, 2012.

[15] K. Nikjoo, M. Aliahmad, S. Sharifi, and M. Sargazi, "Photon correlation spectroscopy and SAXS study of cylindrical to spherical transition in the AOT microemulsion by changing solvent," Soft Nanoscience Letters, vol. 2, no. 2, pp. 17-21, 2012.

[16] S. Sharifi, M. R. Mohammadi, M. Aliahmad, O. Marti, and M. Amirkhani, "The effect of TBAC on the collective diffusion coefficient and morphology of AOT microemulsion at $\mathrm{X}=6.7$," Physics and Chemistry of Liquids, vol. 51, no. 4, pp. 469-479, 2013.

[17] C.-A. Peng and F. Huang, "Formation of perfluorocarbon microemulsion by fluorinated polyethylene glycol," Journal of Dispersion Science and Technology, vol. 29, no. 1, pp. 46-51, 2008.

[18] M. Bisceglia, D. H. Kurlat, J. P. Chéret, and B. Ginzberg, "Measurements of the Kerr effect in W/O microemulsions up to the proximity of a $\mathrm{W}_{\mathrm{II}} \rightarrow \mathrm{W}_{\mathrm{III}}$ transition," Physics and Chemistry of Liquids, vol. 25, no. 2, pp. 127-134, 1993.

[19] S. Sharifi, G. V. Jensen, J. S. Pedersen, O. Marti, and M. Amirkhani, "The mixture of poly(propylene-glycol)-blockpoly(ethylene-glycol)-block-PPG with $\mathrm{C}_{12} \mathrm{E}_{5}$ microemulsion," Physics and Chemistry of Liquids, vol. 52, no. 1, pp. 113-121, 2014.

[20] S. Sharifi, O. Marti, S. S. Funari, and M. Amirkhani, "The effect of different polymer length on water droplets of reverse AOT microemulsion," Physics and Chemistry of Liquids, vol. 51, no. 5, pp. 586-594, 2013.

[21] M. Amirkhani, S. Sharifi, and O. Marti, "The effect of simultaneous size reduction and transient network formation on the dynamics of microemulsions," Journal of Physics D: Applied Physics, vol. 45, no. 36, Article ID 365302, 2012. 
[22] C. Bordesa, V. Fréville, E. Ruffin et al., "Determination of poly( $\varepsilon$ caprolactone) solubility parameters: application to solvent substitution in a microencapsulation process," International Journal of Pharmaceutics, vol. 383, pp. 236-243, 2010.

[23] M. Nayeri, M. Zackrisson, and J. Bergenholtz, "Scattering functions of core-shell-struct ured hard spheres with Schulzdistributed radii," Journal of Physical Chemistry B, vol. 113, no. 24, pp. 8296-8302, 2009.

[24] M. Zackrisson, R. Andersson, and J. Bergenholtz, "Depletion interactions in model microemulsions," Langmuir, vol. 20, no. 8, pp. 3080-3089, 2004.

[25] S. Sharifi and M. Amirkhani, "Light scattering study of mixture of polyethylene glycol with $\mathrm{C}_{12} \mathrm{E}_{5}$ microemulsion," Soft Nanoscience Letters, vol. 1, no. 3, pp. 76-80, 2011.

[26] J. Brunner-Popela and O. Glatter, "Small-angle scattering of interacting particles. I. Basic principles of a global evaluation technique," Journal of Applied Crystallography, vol. 30, no. 4, pp. 431-442, 1997. 

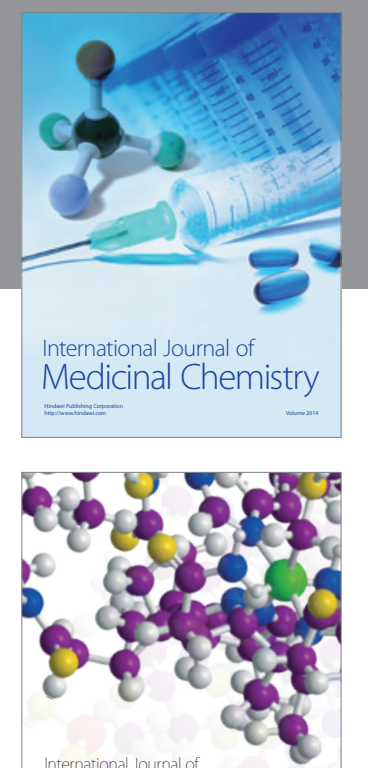

\section{Carbohydrate} Chemistry

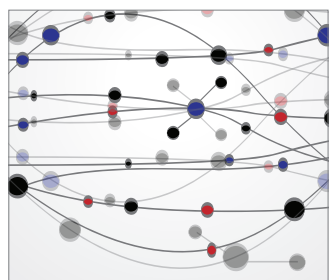

The Scientific World Journal
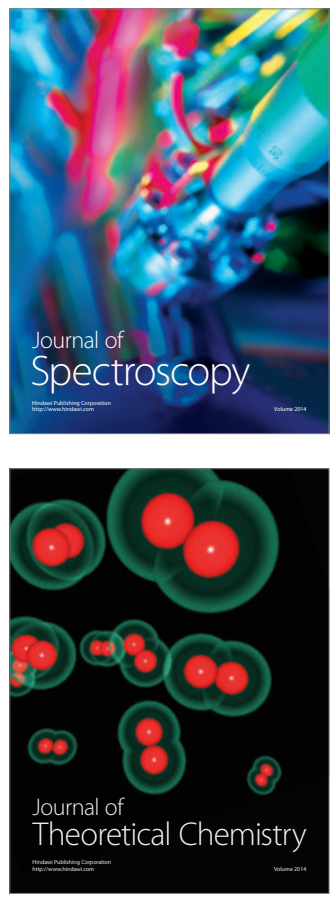
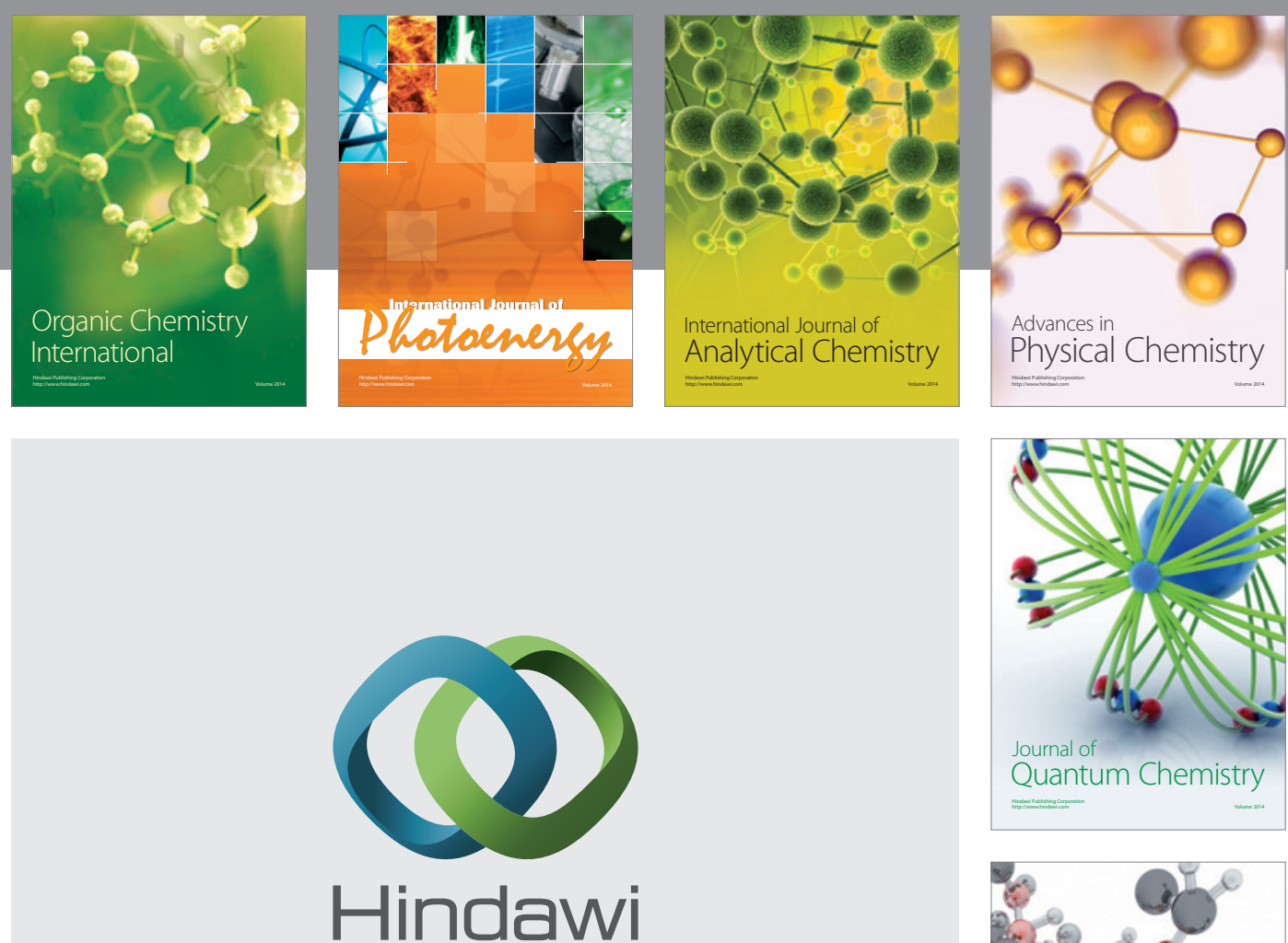

Submit your manuscripts at

http://www.hindawi.com

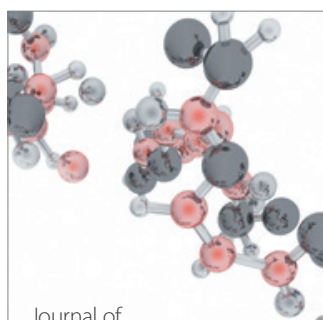

Analytical Methods

in Chemistry

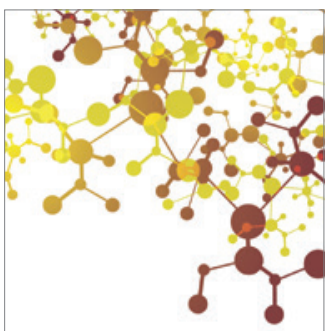

Journal of

Applied Chemistry

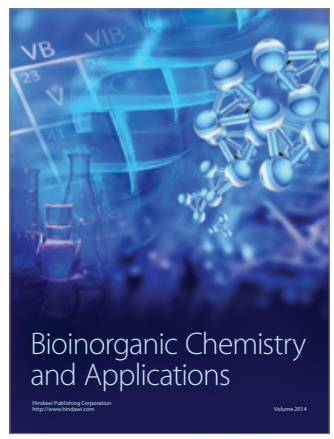

Inorganic Chemistry
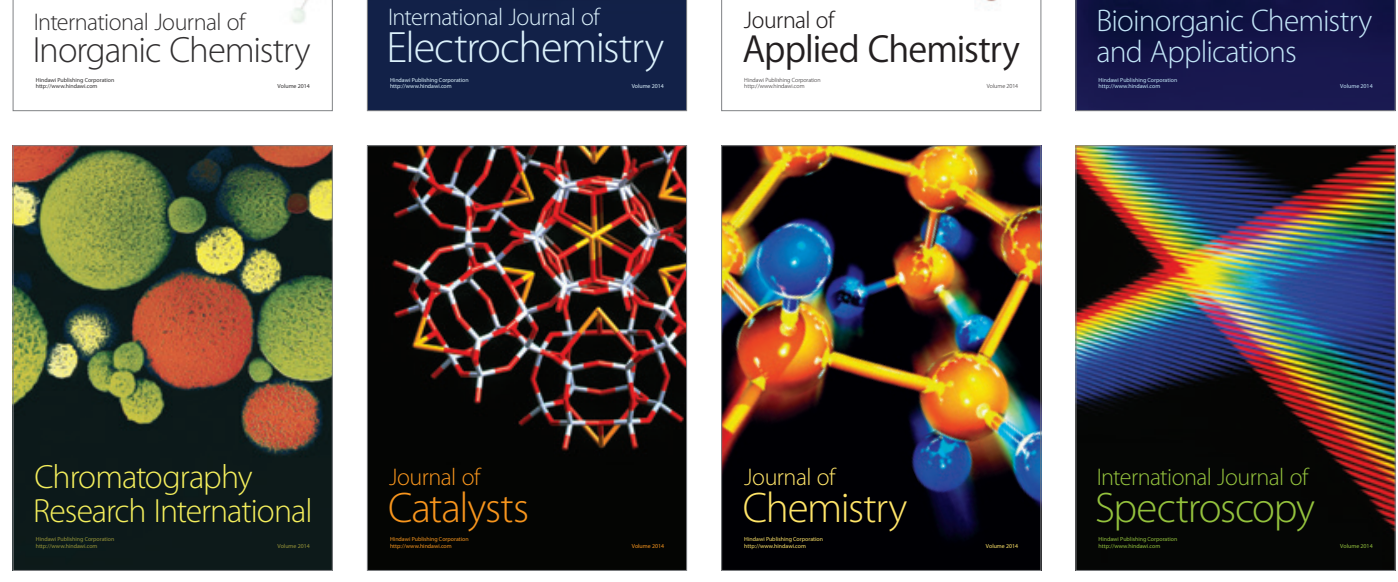